Supporting files

\title{
Proteome Modification in Tomato Plants upon Long-term Aluminum Treatment
}

Suping Zhou ${ }^{1 *}$, Ikenna Okekeogbu ${ }^{1}$,Sasikiran Sangireddy ${ }^{1}$, Zhujia Ye $^{1}$, Hui Li $^{1}$, Sarabjit Bhatti $^{1}$, Dafeng Hui ${ }^{1}$, Daniel W. McDonald ${ }^{2}$, Yong Yang ${ }^{3}$, Shree Giri ${ }^{3}$, Kevin J. Howe ${ }^{3}$ Tara Fish $^{3}$, Theodore W. Thannhauser ${ }^{3 *}$

${ }^{1}$ Department of Agricultural and Environmental Sciences, College of Agriculture, Human and Natural Sciences, Tennessee State University, 3500 John A Merritt Blvd, Nashville, TN 37209

${ }^{2}$ Phenotype Screening Corporation, 4028 Papermill Road, Knoxville, TN 37909

${ }^{3}$ RW Holley Center for Agriculture and Health, Plant, Soil and Nutrition Research Unit, USDAARS, Tower Rd, Ithaca, NY 14853

Table of contents

Figure S1. Tomato plants after four-months of Al treatment.

Figure S2. Principal component analysis (PCA) of proteomes from Al-treated and non-treated tomato tissues

Figure S3. Normal distribution of protein $\log 2$ relative abundances of Al-treated versus nontreated tomato tissues

Figure S4. Enriched GOs for biological processes of Al-induced tomato proteins Table S1. The mass spectrometry proteomics data of the Al-treated tomato iTRAQ experiments in PRIDE repository

Table S2. Summary of Al-induced tomato proteomes identified in the iTRAQ experiments. Table S3. Significantly changed proteins induced by Al treatments in tomatoes 
Table S4. Leaf proteins listed in functional pathway analysis using Mapman

Table S5. List of Al-induced significantly changed proteins in the enrichment GOs of biological processes in tomato

Table S6. Dataset associated with Figure S4

Table S7. Proteins identified with two or more unique peptides and quantified in iTRAQ experiments of tomato tissues 
Supplementary figure legends

Figure S1. Tomato plants after four-months of Al treatment. Photograph courtesy of Suping Zhou. Images in Figure S-1 are free domain. S-2

A. Tomato plants, showing red tomatoes from which seeds were collected, and yellowing leaves that were excluded from mineral element analysis (arrows point to leaves with yellow blotches on Al-treated and non-treated tomato plants) (1); a close-up view of crown (2); top leaflet samples used for protein extraction (3); tomato roots developed in hydroponic tanks in the Al-treated and non-treated experiments (4).

B. Root systems of Al-treated and untreated tomato plants. Tomato plants were grown for four months in Magnavaca's solution supplemented with $7.5 \mu \mathrm{M}$ active $\mathrm{Al}^{3+}, \mathrm{pH} 4.5$, and the control non-treated plants were in Magnavaca's solution only. The root systems were imaged in a soft-tissue $\mathrm{x}$-ray imaging chamber. The x-ray operating point was set to 25 $\mathrm{KV}$ at 800 microamperes. The root systems were scanned to acquire $80 \mathrm{x}$-ray images of each root system. The optical resolution of each X-ray image is 60 microns. The 80 individual images were stitched into a single composite image of the entire root system. The composite X-ray image was then processed by RhizoTraits software to extract key root traits (Phenotype Screening Corporation, Knoxville, TN, USA).

Figure S2. Principal component analysis (PCA) of proteomes from Al-treated and nontreated tomato tissues. The $\log _{2}$ fold-change data of the constitutive peptides from the whole proteome were subjected to PCA analysis. For root and leaf tissues, the four proteomes from the same treatment condition were clustered together, and they were well-separated for Altreated or non-treated control conditions. For embryo and seed coats, samples from Al- 
treated conditions were not separated into different components from the non-treated-control conditions. Note: Al-treated four replicates: T1, T2, T3, T4; non-treated control replicates: $\mathrm{C} 1, \mathrm{C} 2, \mathrm{C} 3, \mathrm{C} 4$.

Figure S3. Normal distribution of protein $\log 2$ relative abundances of Al-treated versus nontreated tomato tissues. Protein abundances were estimated using two or more unique trptic peptides which were quantified using the method of isobaric tags for relative and absolute quantitation (iTRAQ). Four biological replicates were included for Al-treated and nontreated experiments for tomato root, leaf, embryo and seed coat tissues.

Figure S4. Enriched GOs for biological processes. Protein datasets containing information of gene accession, ratio (Al-treated/non-treated control samples), and $p$ value from FDR test were uploaded into the data management directory in Plant MetGenMap (http://bioinfo.bti.cornell.edu/cgi-bin/MetGenMAP). These proteins were analyzed using the GO term function module. The gene expression data parameters were up-regulated cutoff at $(1+$ two standard deviations $)$, down-regulated cutoff at ( 1 - two standard deviations $)$, and $p$ value cutoff at 0.05 . Original data for generating this graph is given in S-6. Note: Up: Alinduced proteins, Dn: A-repressed proteins. 


\section{Figure S1}

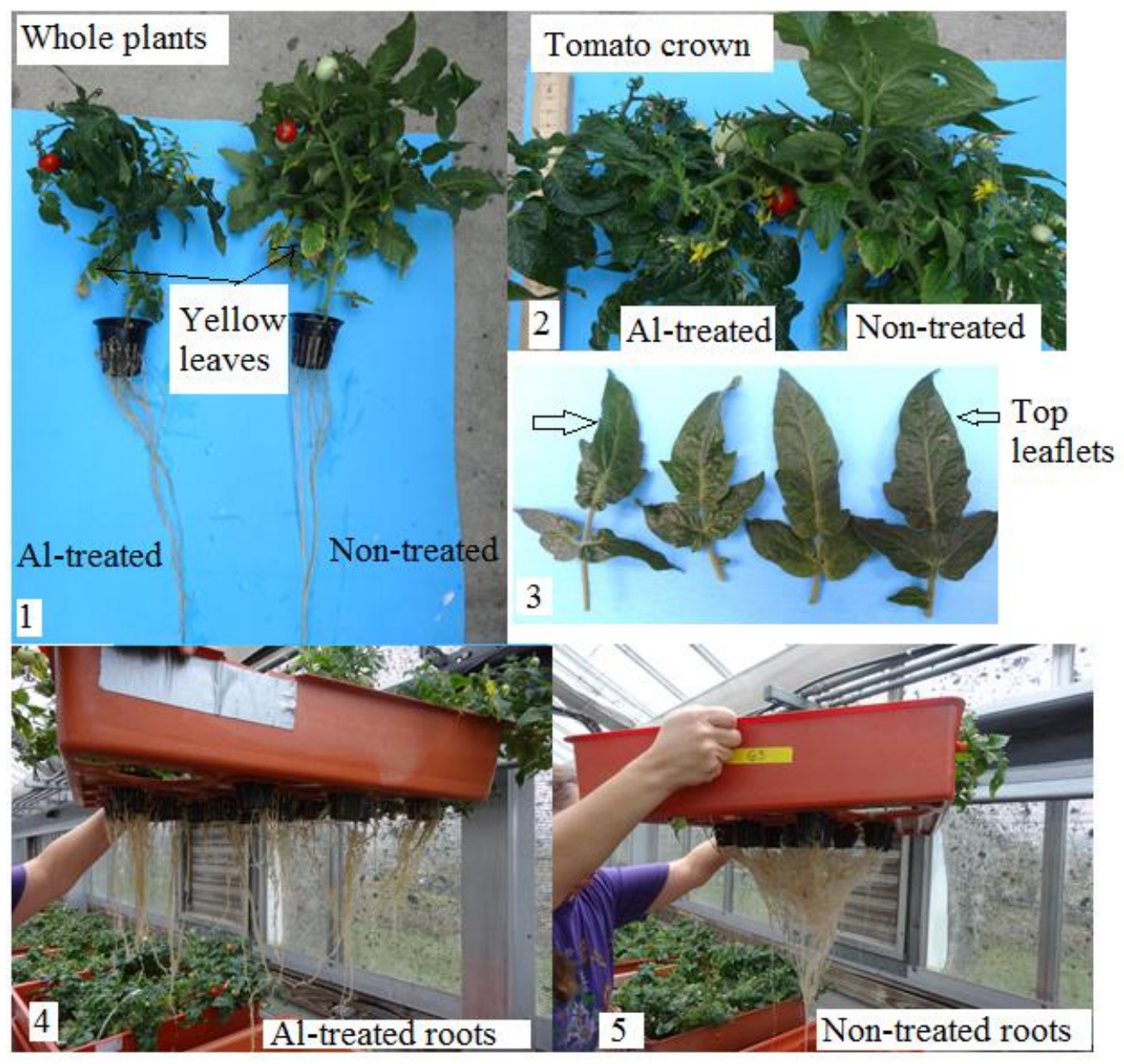

Figure S1A 

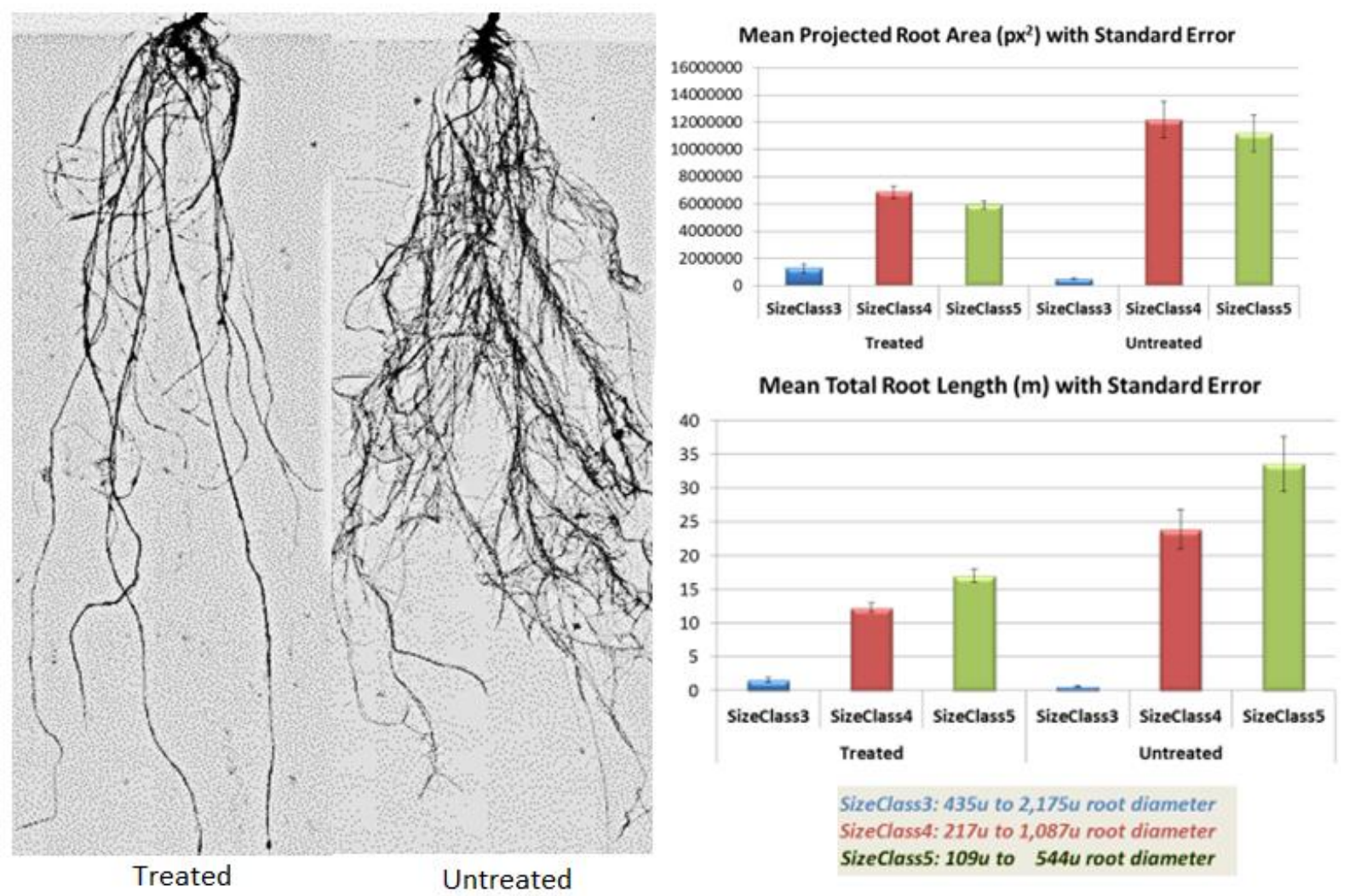

SizeClass3: 435u to 2,175u root diameter SizeClass4: 217u to 1,087u root diameter SizeClass5: $109 u$ to $544 u$ root diameter

Figure S1B 
Figure S2
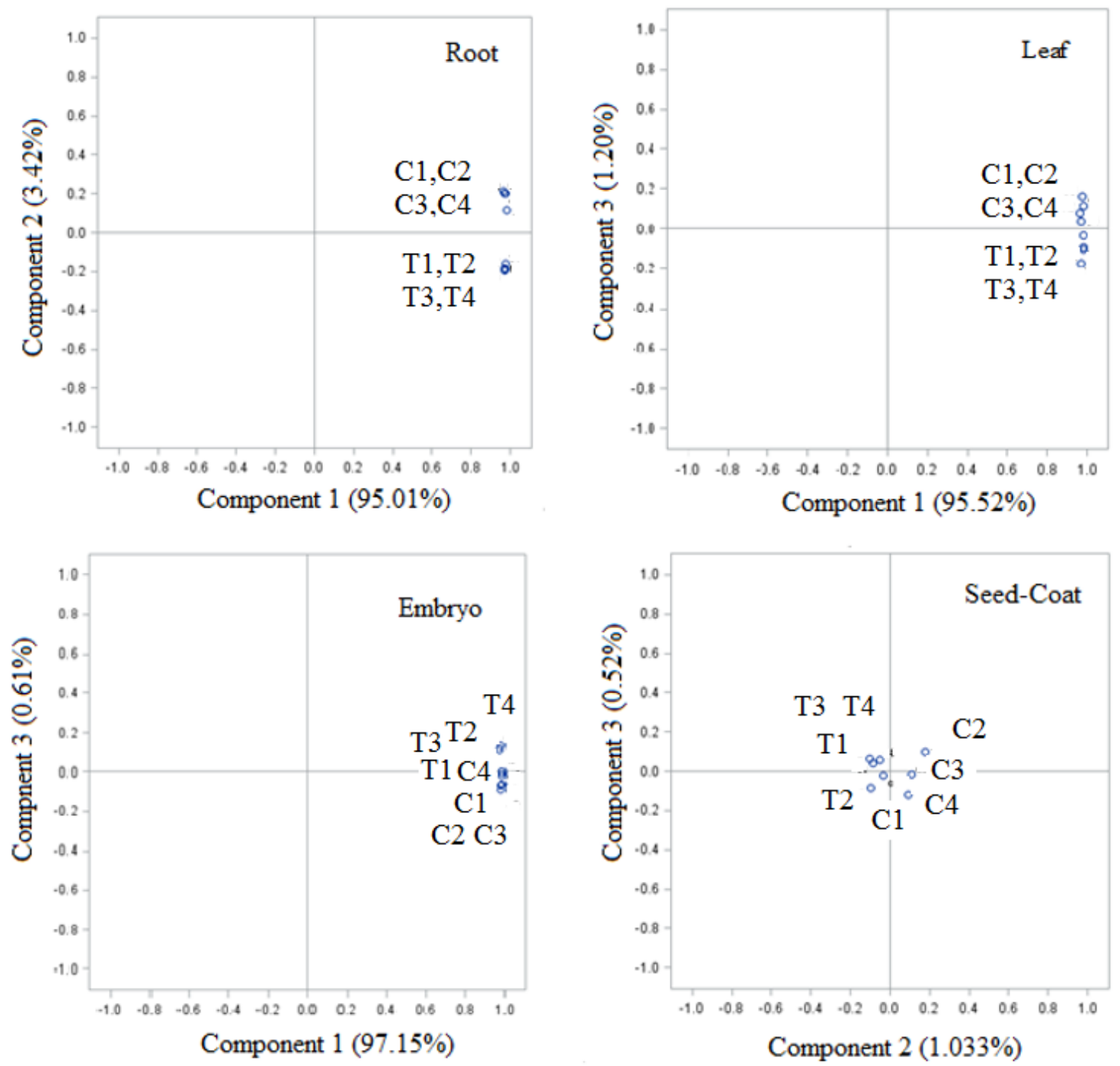
Figure S3
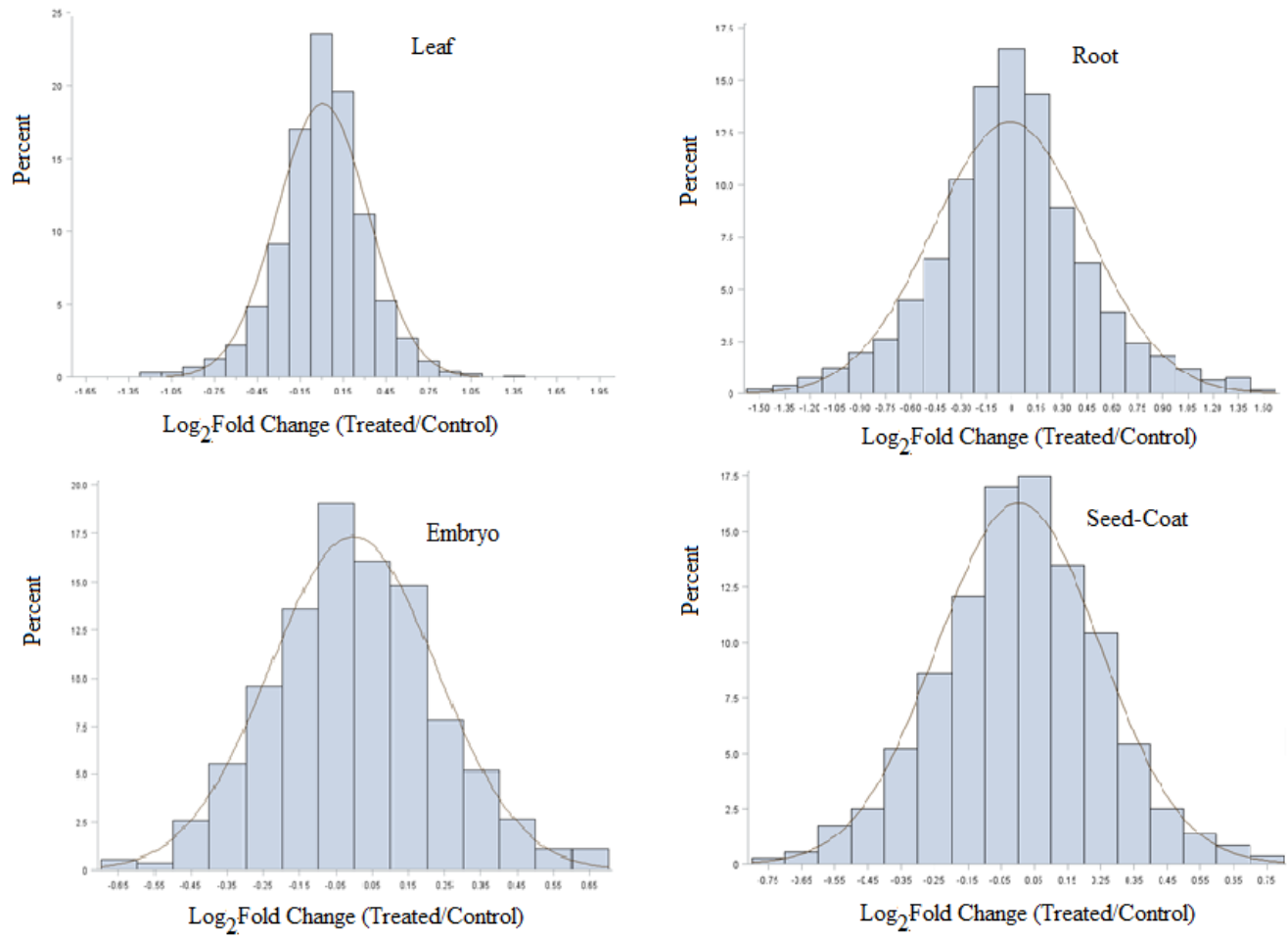
Figure S4

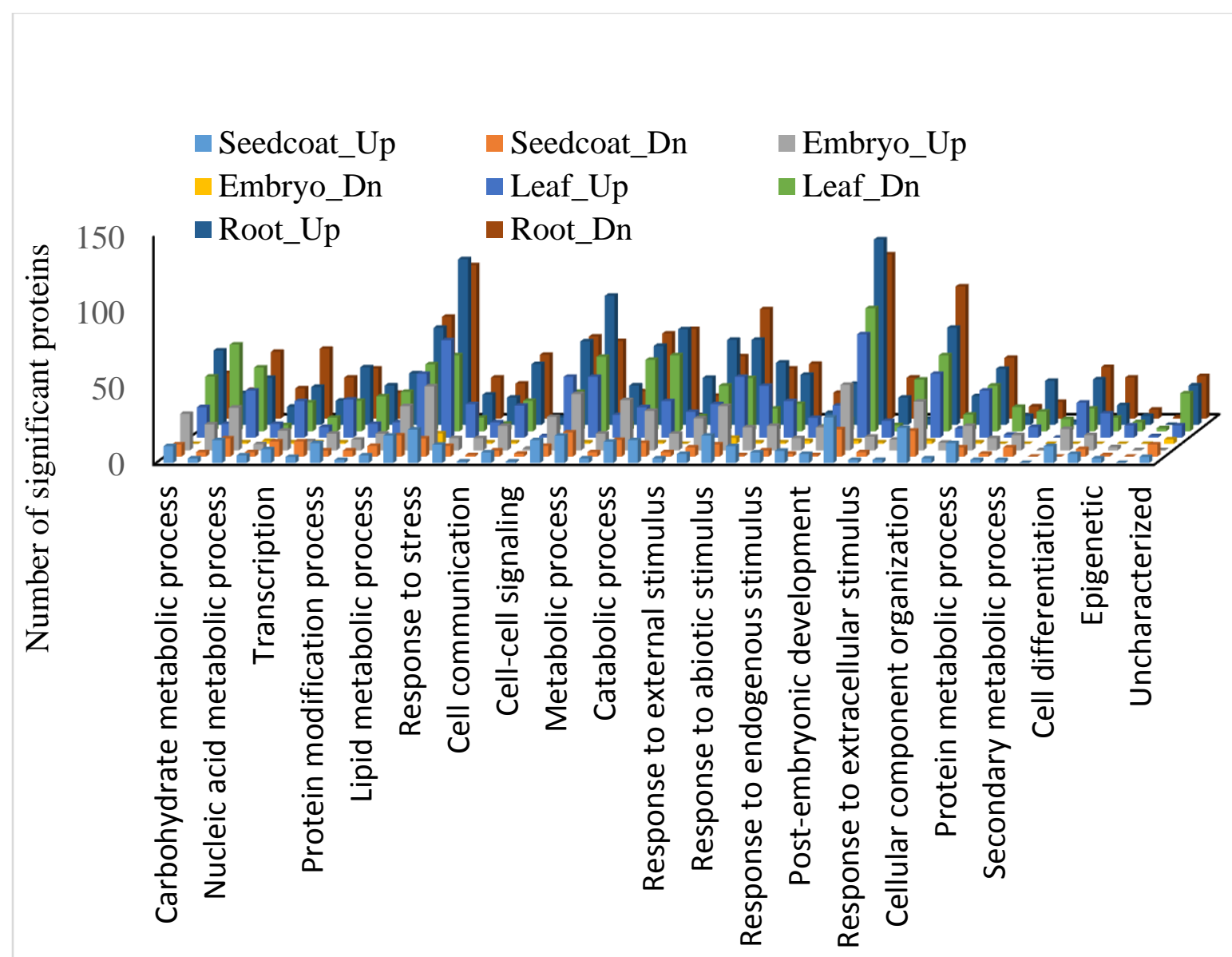

Enriched GOs for biological functions of Al-induced tomato proteomes 
Table S1 The mass spectrometry proteomics data set identifiers of the Al-treated tomato iTRAQ experiments in the Proteomics Identifications Database (PRIDE) repository of the ProteomeXchange Consortium.

\begin{tabular}{ccc} 
project Name & accession & DOI \\
\hline $\begin{array}{c}\text { "Protein expression in tomato tissues } \\
\text { as a function of A13+ stress Exp 1" }\end{array}$ & PXD003575 & $10.6019 /$ PXD003575 \\
$\begin{array}{c}\text { Protein expression in tomato tissues } \\
\text { as a function of Al3+ stress Exp 2" }\end{array}$ & PXD003602 & $10.6019 /$ PXD003602 \\
$\begin{array}{c}\text { Protein expression in tomato tissues } \\
\text { as a function of A13+ stress Exp 4" }\end{array}$ & PXD003601 & $10.6019 /$ PXD003601 \\
$\begin{array}{l}\text { Protein expression in tomato tissues } \\
\text { as a function of Al3+ stress Exp 5" }\end{array}$ & PXD003600 & $10.6019 /$ PXD003600 \\
\hline
\end{tabular}


Table S2. Proteins identified in root, leaf, seed coat and embryo tissues from Al-treated tomato plants

tissues number of proteins quantified ${ }^{a} \quad$ significantly changed proteins $^{\mathrm{b}}$

\section{$\underline{\text { Al-induced } \quad \text { Al-repressed }}$}

leaf

4339

102

143

root

3651

149

174

Seed-coat

1088

28

24

embryo

1077

37

19

\footnotetext{
${ }^{a}$ Number of proteins that were quantified using > 2 unique peptides in ITRAQ experiment;

${ }^{\mathrm{b}}$ Number of proteins identified with $>2$ unique peptides, passing $t$-test and FDR test $(p<0.05)$, and with fold change values greater than two standard deviations from the means of proteins in the same proteome.
} 
Table S3. Significantly changed proteins induced by Al treatments in tomatoes ${ }^{\mathrm{a}}$

\begin{tabular}{|c|c|c|}
\hline \multicolumn{2}{|c|}{ accession $^{b} \quad \log _{2}$ fold change $(T-C)^{c}$} & \multirow[t]{2}{*}{$\operatorname{ratio}(\mathrm{T} / \mathrm{C})^{\mathrm{d}}$} \\
\hline Roots & & \\
\hline solyc09g057570.2.1 & -5.18 & 0.03 \\
\hline solyc07g062400.2.1 & -2.53 & 0.17 \\
\hline solyc10g007350.2.1 & -2.52 & 0.17 \\
\hline solyc08g067500.1.1 & -2.50 & 0.18 \\
\hline solyc01g111080.2.1 & -2.37 & 0.19 \\
\hline solyc09g010800.2.1 & -2.32 & 0.20 \\
\hline solyc03g119210.1.1 & -2.21 & 0.22 \\
\hline solyc12g099120.1.1 & -2.10 & 0.23 \\
\hline solyc01g006470.1.1 & -2.05 & 0.24 \\
\hline solyc11g006750.1.1 & -2.03 & 0.24 \\
\hline solyc04g056350.1.1 & -1.98 & 0.25 \\
\hline solyc00g071180.2.1 & -1.86 & 0.28 \\
\hline solyc04g071620.2.1 & -1.84 & 0.28 \\
\hline solyc12g008560.1.1 & -1.83 & 0.28 \\
\hline solyc02g080600.1.1 & -1.81 & 0.28 \\
\hline solyc12g099490.1.1 & -1.77 & 0.29 \\
\hline solyc03g114170.2.1 & -1.70 & 0.31 \\
\hline solyc12g014290.1.1 & -1.69 & 0.31 \\
\hline solyc06g065840.2.1 & -1.67 & 0.31 \\
\hline solyc07g039450.2.1 & -1.65 & 0.32 \\
\hline solyc11g065270.1.1 & -1.60 & 0.33 \\
\hline solyc02g088930.2.1 & -1.57 & 0.34 \\
\hline solyc05g008140.2.1 & -1.57 & 0.34 \\
\hline solyc08g005590.2.1 & -1.55 & 0.34 \\
\hline solyc04g078070.2.1 & -1.55 & 0.34 \\
\hline solyc02g064730.2.1 & -1.52 & 0.35 \\
\hline solyc10g005100.2.1 & -1.51 & 0.35 \\
\hline solyc08g008330.2.1 & -1.50 & 0.35 \\
\hline solyc08g066540.2.1 & -1.50 & 0.35 \\
\hline solyc06g072220.1.1 & -1.48 & 0.36 \\
\hline solyc08g075830.2.1 & -1.46 & 0.36 \\
\hline solyc11g006500.1.1 & -1.46 & 0.36 \\
\hline solyc06g007540.2.1 & -1.45 & 0.37 \\
\hline solyc01g099520.2.1 & -1.43 & 0.37 \\
\hline solyc01g090190.2.1 & -1.42 & 0.37 \\
\hline solyc03g006510.2.1 & -1.42 & 0.37 \\
\hline solyc07g053020.1.1 & -1.39 & 0.38 \\
\hline solyc03g025800.2.1 & -1.37 & 0.39 \\
\hline solyc09g014450.2.1 & -1.36 & 0.39 \\
\hline solyc01g102310.2.1 & -1.35 & 0.39 \\
\hline
\end{tabular}




\begin{tabular}{|c|c|c|}
\hline solyc05g046010.2.1 & -1.35 & 0.39 \\
\hline solyc06g062510.2.1 & -1.32 & 0.40 \\
\hline solyc02g079060.2.1 & -1.30 & 0.41 \\
\hline solyc05g055170.2.1 & -1.30 & 0.41 \\
\hline solyc09g010120.2.1 & -1.29 & 0.41 \\
\hline solyc09g007430.1.1 & -1.29 & 0.41 \\
\hline solyc09g098270.2.1 & -1.29 & 0.41 \\
\hline solyc07g017570.2.1 & -1.28 & 0.41 \\
\hline solyc07g052540.2.1 & -1.28 & 0.41 \\
\hline solyc08g079630.2.1 & -1.27 & 0.41 \\
\hline solyc02g093820.2.1 & -1.26 & 0.42 \\
\hline solyc08g067510.1.1 & -1.24 & 0.42 \\
\hline solyc04g051710.1.1 & -1.24 & 0.42 \\
\hline solyc04g072450.2.1 & -1.23 & 0.43 \\
\hline solyc05g046020.2.1 & -1.23 & 0.43 \\
\hline solyc01g008360.2.1 & -1.23 & 0.43 \\
\hline solyc02g078540.2.1 & -1.22 & 0.43 \\
\hline solyc12g010060.1.1 & -1.22 & 0.43 \\
\hline solyc12g094700.1.1 & -1.21 & 0.43 \\
\hline solyc12g089370.1.1 & -1.19 & 0.44 \\
\hline solyc09g007090.2.1 & -1.19 & 0.44 \\
\hline solyc12g099570.1.1 & -1.19 & 0.44 \\
\hline solyc01g111940.2.1 & -1.19 & 0.44 \\
\hline solyc12g005270.1.1 & -1.18 & 0.44 \\
\hline solyc11g005880.1.1 & -1.17 & 0.44 \\
\hline solyc03g007650.1.1 & -1.17 & 0.44 \\
\hline solyc11g065940.1.1 & -1.17 & 0.45 \\
\hline solyc01g067850.2.1 & -1.16 & 0.45 \\
\hline solyc02g091990.2.1 & -1.16 & 0.45 \\
\hline solyc03g025850.2.1 & -1.16 & 0.45 \\
\hline solyc11g006690.1.1 & -1.16 & 0.45 \\
\hline solyc03g097950.2.1 & -1.15 & 0.45 \\
\hline solyc12g008950.1.1 & -1.14 & 0.45 \\
\hline solyc03g117970.2.1 & -1.14 & 0.46 \\
\hline solyc10g006560.2.1 & -1.13 & 0.46 \\
\hline solyc07g052530.2.1 & -1.13 & 0.46 \\
\hline solyc00g072400.2.1 & -1.12 & 0.46 \\
\hline solyc02g062540.2.1 & -1.12 & 0.46 \\
\hline solyc05g012060.2.1 & -1.11 & 0.46 \\
\hline solyc06g008290.2.1 & -1.11 & 0.46 \\
\hline solyc10g008120.2.1 & -1.11 & 0.46 \\
\hline solyc09g059620.2.1 & -1.10 & 0.47 \\
\hline solyc12g099820.1.1 & -1.09 & 0.47 \\
\hline solyc03g121520.2.1 & -1.09 & 0.47 \\
\hline solyc09g082710.2.1 & -1.09 & 0.47 \\
\hline
\end{tabular}




\begin{tabular}{|c|c|c|}
\hline solyc08g078900.1.1 & -1.09 & 0.47 \\
\hline solyc07g045340.2.1 & -1.08 & 0.47 \\
\hline solyc03g097380.2.1 & -1.08 & 0.47 \\
\hline solyc04g082200.2.1 & -1.07 & 0.47 \\
\hline solyc08g065900.2.1 & -1.06 & 0.48 \\
\hline solyc02g085390.2.1 & -1.06 & 0.48 \\
\hline solyc12g094660.1.1 & -1.05 & 0.48 \\
\hline solyc04g011620.2.1 & -1.05 & 0.48 \\
\hline solyc01g079610.2.1 & -1.05 & 0.48 \\
\hline solyc12g011300.1.1 & -1.04 & 0.48 \\
\hline solyc01g080890.2.1 & -1.04 & 0.49 \\
\hline solyc01g096960.2.1 & -1.03 & 0.49 \\
\hline solyc01g008990.2.1 & -1.03 & 0.49 \\
\hline solyc09g010200.2.1 & -1.03 & 0.49 \\
\hline solyc03g119160.2.1 & -1.02 & 0.49 \\
\hline solyc02g077740.2.1 & -1.01 & 0.50 \\
\hline solyc03g121360.1.1 & -1.01 & 0.50 \\
\hline solyc04g009060.2.1 & -1.01 & 0.50 \\
\hline solyc05g007790.2.1 & -1.01 & 0.50 \\
\hline solyc05g049950.2.1 & -1.01 & 0.50 \\
\hline solyc07g009020.1.1 & -1.01 & 0.50 \\
\hline solyc02g092270.2.1 & -1.00 & 0.50 \\
\hline solyc04g005620.2.1 & -1.00 & 0.50 \\
\hline solyc01g094370.2.1 & -1.00 & 0.50 \\
\hline solyc02g032030.1.1 & -0.99 & 0.50 \\
\hline solyc08g007220.2.1 & -0.99 & 0.50 \\
\hline solyc02g031740.2.1 & -0.99 & 0.50 \\
\hline solyc01g111200.2.1 & -0.99 & 0.50 \\
\hline solyc05g006390.1.1 & -0.99 & 0.50 \\
\hline solyc08g066160.2.1 & -0.98 & 0.51 \\
\hline solyc02g086680.2.1 & -0.98 & 0.51 \\
\hline solyc08g075400.2.1 & -0.98 & 0.51 \\
\hline solyc02g077880.2.1 & -0.98 & 0.51 \\
\hline solyc12g014310.1.1 & -0.98 & 0.51 \\
\hline solyc10g085970.1.1 & -0.98 & 0.51 \\
\hline solyc06g060080.2.1 & -0.97 & 0.51 \\
\hline solyc01g111260.2.1 & -0.97 & 0.51 \\
\hline solyc10g007180.2.1 & -0.96 & 0.51 \\
\hline solyc11g005450.1.1 & -0.96 & 0.51 \\
\hline solyc04g076190.1.1 & -0.96 & 0.52 \\
\hline solyc06g008280.2.1 & -0.95 & 0.52 \\
\hline solyc01g100500.2.1 & -0.95 & 0.52 \\
\hline solyc01g104840.2.1 & -0.95 & 0.52 \\
\hline solyc05g006750.2.1 & -0.94 & 0.52 \\
\hline
\end{tabular}




\begin{tabular}{|c|c|c|}
\hline solyc06g005360.2.1 & -0.94 & 0.52 \\
\hline solyc01g079870.2.1 & -0.94 & 0.52 \\
\hline solyc11g066970.1.1 & -0.94 & 0.52 \\
\hline solyc01g079960.2.1 & -0.94 & 0.52 \\
\hline solyc02g064970.2.1 & -0.94 & 0.52 \\
\hline solyc05g054120.1.1 & -0.93 & 0.52 \\
\hline solyc07g056490.2.1 & -0.93 & 0.52 \\
\hline solyc10g005800.2.1 & -0.93 & 0.52 \\
\hline solyc07g008170.2.1 & -0.93 & 0.53 \\
\hline solyc06g073360.2.1 & -0.93 & 0.53 \\
\hline solyc06g065470.2.1 & -0.93 & 0.53 \\
\hline solyc11g044230.1.1 & -0.92 & 0.53 \\
\hline solyc04g007960.2.1 & -0.92 & 0.53 \\
\hline solyc03g098470.2.1 & -0.92 & 0.53 \\
\hline solyc12g009590.1.1 & -0.92 & 0.53 \\
\hline solyc07g047740.2.1 & -0.92 & 0.53 \\
\hline solyc09g091910.1.1 & -0.92 & 0.53 \\
\hline solyc09g009210.2.1 & -0.92 & 0.53 \\
\hline solyc06g074000.1.1 & -0.92 & 0.53 \\
\hline solyc02g062270.2.1 & -0.92 & 0.53 \\
\hline solyc05g007940.2.1 & 0.92 & 1.89 \\
\hline solyc09g090010.2.1 & 0.92 & 1.90 \\
\hline solyc03g006140.2.1 & 0.92 & 1.90 \\
\hline solyc09g084450.2.1 & 0.93 & 1.90 \\
\hline solyc04g007790.2.1 & 0.93 & 1.90 \\
\hline solyc04g056570.2.1 & 0.93 & 1.90 \\
\hline solyc03g119230.1.1 & 0.93 & 1.90 \\
\hline solyc09g011760.2.1 & 0.93 & 1.91 \\
\hline solyc03g115630.2.1 & 0.93 & 1.91 \\
\hline solyc12g088050.1.1 & 0.94 & 1.91 \\
\hline solyc02g088390.2.1 & 0.94 & 1.92 \\
\hline solyc02g069800.1.1 & 0.94 & 1.92 \\
\hline solyc07g009520.1.1 & 0.94 & 1.92 \\
\hline solyc01g108080.2.1 & 0.94 & 1.92 \\
\hline solyc04g005040.1.1 & 0.95 & 1.93 \\
\hline solyc12g056390.1.1 & 0.96 & 1.94 \\
\hline solyc01g098810.2.1 & 0.96 & 1.95 \\
\hline solyc10g047650.1.1 & 0.97 & 1.96 \\
\hline solyc09g083080.2.1 & 0.97 & 1.96 \\
\hline solyc04g008770.2.1 & 0.97 & 1.96 \\
\hline solyc07g063680.2.1 & 0.97 & 1.96 \\
\hline solyc08g079980.1.1 & 0.98 & 1.98 \\
\hline solyc03g119080.2.1 & 0.98 & 1.98 \\
\hline solyc07g006570.2.1 & 0.99 & 1.98 \\
\hline solyc04g079470.2.1 & 0.99 & 1.98 \\
\hline
\end{tabular}




\begin{tabular}{|c|c|c|}
\hline solyc03g116580.2.1 & 0.99 & 1.99 \\
\hline solyc08g079970.1.1 & 1.00 & 1.99 \\
\hline solyc04g082770.2.1 & 1.00 & 2.00 \\
\hline solyc04g071900.2.1 & 1.00 & 2.01 \\
\hline solyc12g013900.1.1 & 1.01 & 2.01 \\
\hline solyc04g005050.1.1 & 1.01 & 2.01 \\
\hline solyc06g067980.2.1 & 1.01 & 2.01 \\
\hline solyc09g091260.2.1 & 1.01 & 2.02 \\
\hline solyc12g010390.1.1 & 1.01 & 2.02 \\
\hline solyc03g098760.1.1 & 1.01 & 2.02 \\
\hline solyc02g080500.2.1 & 1.01 & 2.02 \\
\hline solyc05g009000.2.1 & 1.03 & 2.04 \\
\hline solyc01g111040.2.1 & 1.03 & 2.04 \\
\hline solyc09g090980.2.1 & 1.03 & 2.04 \\
\hline solyc08g077910.2.1 & 1.03 & 2.05 \\
\hline solyc08g079900.1.1 & 1.03 & 2.05 \\
\hline solyc12g009300.1.1 & 1.04 & 2.05 \\
\hline solyc07g008120.2.1 & 1.04 & 2.06 \\
\hline solyc03g123620.2.1 & 1.04 & 2.06 \\
\hline solyc10g085430.1.1 & 1.05 & 2.07 \\
\hline solyc04g064770.1.1 & 1.05 & 2.07 \\
\hline solyc02g082270.2.1 & 1.07 & 2.10 \\
\hline solyc12g098940.1.1 & 1.07 & 2.10 \\
\hline solyc02g068530.2.1 & 1.07 & 2.10 \\
\hline solyc03g020010.1.1 & 1.08 & 2.12 \\
\hline solyc08g080590.2.1 & 1.09 & 2.13 \\
\hline solyc08g083380.2.1 & 1.09 & 2.14 \\
\hline solyc09g005700.2.1 & 1.10 & 2.14 \\
\hline solyc01g097270.2.1 & 1.10 & 2.15 \\
\hline solyc04g017590.1.1 & 1.10 & 2.15 \\
\hline solyc07g056170.2.1 & 1.11 & 2.16 \\
\hline solyc04g008490.1.1 & 1.11 & 2.16 \\
\hline solyc10g083290.1.1 & 1.11 & 2.16 \\
\hline solyc03g006700.2.1 & 1.11 & 2.16 \\
\hline solyc01g008620.2.1 & 1.11 & 2.16 \\
\hline solyc02g084240.2.1 & 1.11 & 2.16 \\
\hline solyc12g096620.1.1 & 1.12 & 2.17 \\
\hline solyc01g020320.2.1 & 1.12 & 2.17 \\
\hline solyc11g062350.1.1 & 1.12 & 2.18 \\
\hline solyc07g056190.2.1 & 1.13 & 2.19 \\
\hline solyc08g079930.1.1 & 1.13 & 2.19 \\
\hline solyc01g007630.2.1 & 1.14 & 2.20 \\
\hline solyc09g074890.1.1 & 1.14 & 2.20 \\
\hline solyc01g005980.2.1 & 1.14 & 2.21 \\
\hline
\end{tabular}




\begin{tabular}{|c|c|c|}
\hline solyc06g084570.2.1 & 1.14 & 2.21 \\
\hline solyc01g094430.1.1 & 1.14 & 2.21 \\
\hline solyc01g009810.2.1 & 1.14 & 2.21 \\
\hline solyc09g074860.2.1 & 1.15 & 2.22 \\
\hline solyc03g007370.2.1 & 1.16 & 2.23 \\
\hline solyc06g034110.2.1 & 1.16 & 2.24 \\
\hline solyc08g007460.2.1 & 1.16 & 2.24 \\
\hline solyc01g095490.2.1 & 1.17 & 2.25 \\
\hline solyc02g070130.1.1 & 1.18 & 2.26 \\
\hline solyc12g014420.1.1 & 1.19 & 2.27 \\
\hline solyc08g013880.2.1 & 1.20 & 2.30 \\
\hline solyc09g042700.2.1 & 1.21 & 2.31 \\
\hline solyc04g009690.1.1 & 1.22 & 2.32 \\
\hline solyc10g008340.2.1 & 1.22 & 2.32 \\
\hline solyc02g080070.2.1 & 1.24 & 2.37 \\
\hline solyc03g098670.1.1 & 1.25 & 2.38 \\
\hline solyc08g079870.1.1 & 1.27 & 2.40 \\
\hline solyc05g056580.2.1 & 1.28 & 2.42 \\
\hline solyc08g013930.2.1 & 1.28 & 2.43 \\
\hline solyc01g097240.2.1 & 1.30 & 2.47 \\
\hline solyc09g091000.2.1 & 1.30 & 2.47 \\
\hline solyc00g174340.1.1 & 1.30 & 2.47 \\
\hline solyc02g086710.2.1 & 1.31 & 2.47 \\
\hline solyc09g084490.2.1 & 1.31 & 2.48 \\
\hline solyc04g071860.2.1 & 1.31 & 2.48 \\
\hline solyc10g076200.1.1 & 1.32 & 2.49 \\
\hline solyc07g006560.2.1 & 1.32 & 2.49 \\
\hline solyc12g017460.1.1 & 1.33 & 2.51 \\
\hline solyc08g074690.2.1 & 1.34 & 2.53 \\
\hline solyc02g038690.1.1 & 1.34 & 2.54 \\
\hline solyc02g081330.2.1 & 1.35 & 2.54 \\
\hline solyc06g053430.2.1 & 1.35 & 2.55 \\
\hline solyc08g077180.2.1 & 1.36 & 2.56 \\
\hline solyc05g053440.2.1 & 1.36 & 2.57 \\
\hline solyc02g076980.2.1 & 1.38 & 2.60 \\
\hline solyc12g013810.1.1 & 1.38 & 2.61 \\
\hline solyc03g119500.1.1 & 1.39 & 2.61 \\
\hline solyc10g075100.1.1 & 1.39 & 2.62 \\
\hline solyc02g077590.1.1 & 1.39 & 2.63 \\
\hline solyc09g090970.2.1 & 1.40 & 2.65 \\
\hline solyc08g014300.2.1 & 1.41 & 2.65 \\
\hline solyc06g082730.2.1 & 1.42 & 2.67 \\
\hline solyc02g079440.1.1 & 1.42 & 2.68 \\
\hline solyc01g056590.1.1 & 1.43 & 2.69 \\
\hline solyc08g080620.1.1 & 1.44 & 2.72 \\
\hline
\end{tabular}




\begin{tabular}{|c|c|c|}
\hline solyc12g005720.1.1 & 1.45 & 2.72 \\
\hline solyc09g007350.2.1 & 1.45 & 2.74 \\
\hline solyc02g082740.1.1 & 1.45 & 2.74 \\
\hline solyc01g067740.2.1 & 1.50 & 2.83 \\
\hline solyc09g008670.2.1 & 1.51 & 2.84 \\
\hline solyc02g065090.2.1 & 1.51 & 2.85 \\
\hline solyc08g076340.2.1 & 1.52 & 2.87 \\
\hline solyc07g064600.2.1 & 1.54 & 2.91 \\
\hline solyc00g128870.2.1 & 1.56 & 2.96 \\
\hline solyc08g007260.1.1 & 1.57 & 2.97 \\
\hline solyc03g098740.1.1 & 1.57 & 2.97 \\
\hline solyc11g072930.1.1 & 1.61 & 3.06 \\
\hline solyc11g019910.1.1 & 1.62 & 3.07 \\
\hline solyc08g006860.2.1 & 1.64 & 3.12 \\
\hline solyc03g116590.2.1 & 1.65 & 3.14 \\
\hline solyc05g008190.2.1 & 1.67 & 3.17 \\
\hline solyc01g006660.1.1 & 1.67 & 3.18 \\
\hline solyc06g053210.2.1 & 1.67 & 3.19 \\
\hline solyc01g079980.2.1 & 1.72 & 3.29 \\
\hline solyc02g089080.2.1 & 1.74 & 3.33 \\
\hline solyc02g079510.2.1 & 1.76 & 3.39 \\
\hline solyc03g043710.1.1 & 1.78 & 3.44 \\
\hline solyc02g081290.2.1 & 1.80 & 3.49 \\
\hline solyc06g069440.2.1 & 1.89 & 3.71 \\
\hline solyc11g066390.1.1 & 1.93 & 3.80 \\
\hline solyc02g079500.2.1 & 1.94 & 3.82 \\
\hline solyc01g094040.2.1 & 1.95 & 3.86 \\
\hline solyc05g052970.2.1 & 1.97 & 3.91 \\
\hline solyc06g075750.1.1 & 2.02 & 4.06 \\
\hline solyc10g084200.1.1 & 2.05 & 4.13 \\
\hline solyc02g063480.2.1 & 2.08 & 4.22 \\
\hline solyc01g006970.2.1 & 2.09 & 4.26 \\
\hline solyc03g116700.2.1 & 2.15 & 4.45 \\
\hline solyc02g077040.2.1 & 2.17 & 4.49 \\
\hline solyc10g085170.1.1 & 2.29 & 4.89 \\
\hline solyc08g079670.2.1 & 2.33 & 5.03 \\
\hline solyc01g009400.2.1 & 2.42 & 5.33 \\
\hline solyc07g061950.2.1 & 2.44 & 5.43 \\
\hline solyc07g009230.2.1 & 2.44 & 5.44 \\
\hline solyc01g097470.2.1 & 2.51 & 5.68 \\
\hline solyc07g055160.2.1 & 2.68 & 6.40 \\
\hline solyc01g109560.2.1 & 2.68 & 6.41 \\
\hline solyc12g013490.1.1 & 2.83 & 7.09 \\
\hline solyc06g054620.2.1 & 2.95 & 7.70 \\
\hline
\end{tabular}




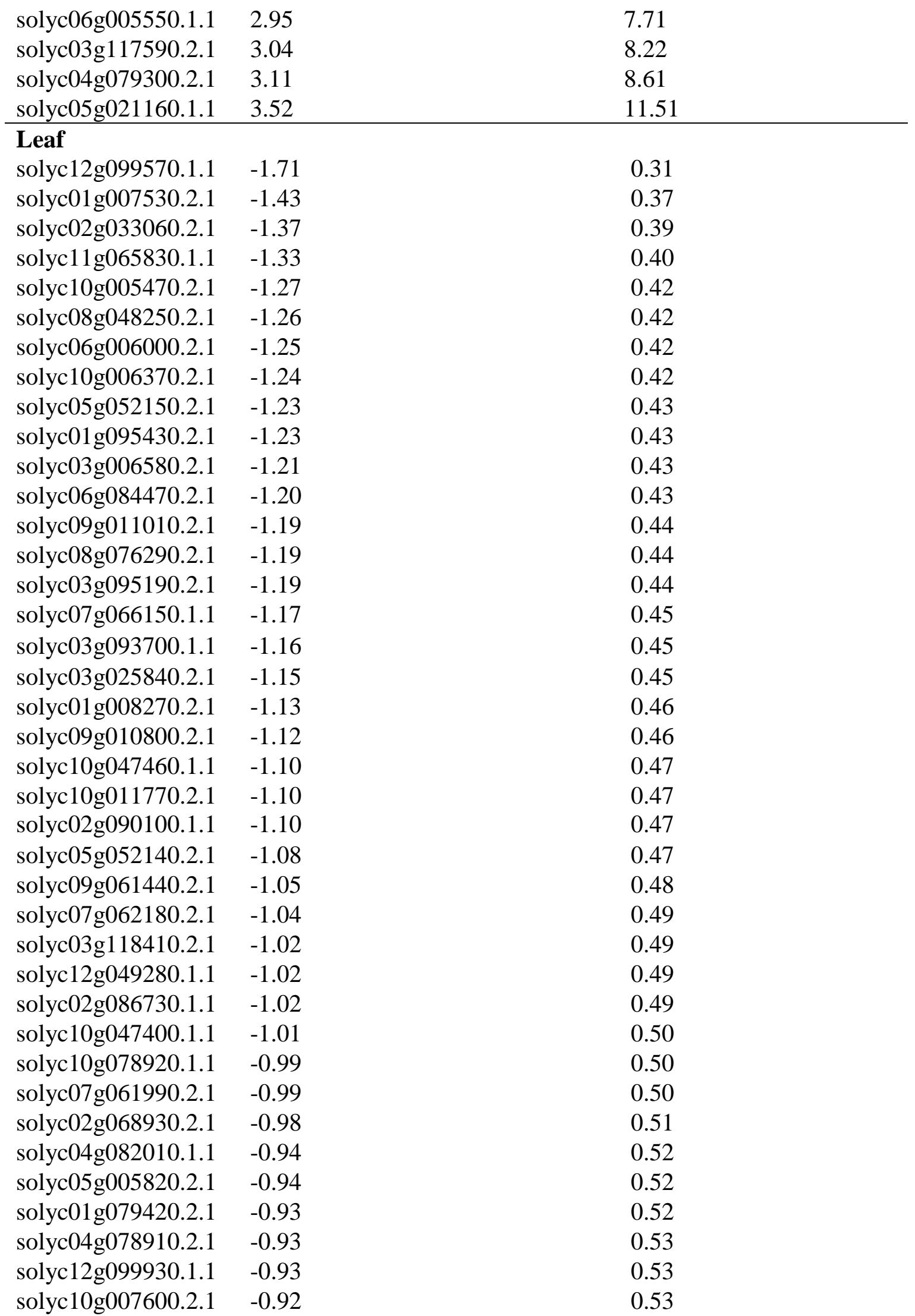




\begin{tabular}{|c|c|c|}
\hline solyc07g056490.2.1 & -0.92 & 0.53 \\
\hline solyc01g103220.2.1 & -0.91 & 0.53 \\
\hline solyc00g231780.1.1 & -0.91 & 0.53 \\
\hline solyc06g065520.2.1 & -0.91 & 0.53 \\
\hline solyc02g087150.2.1 & -0.90 & 0.54 \\
\hline solyc04g011560.2.1 & -0.89 & 0.54 \\
\hline solyc02g086740.1.1 & -0.89 & 0.54 \\
\hline solyc07g054960.1.1 & -0.88 & 0.54 \\
\hline solyc10g005660.2.1 & -0.88 & 0.54 \\
\hline solyc01g068400.2.1 & -0.88 & 0.54 \\
\hline solyc12g027720.1.1 & -0.88 & 0.54 \\
\hline solyc10g005050.2.1 & -0.87 & 0.55 \\
\hline solyc10g045240.1.1 & -0.85 & 0.55 \\
\hline solyc09g084480.2.1 & -0.85 & 0.55 \\
\hline solyc06g066620.2.1 & -0.85 & 0.55 \\
\hline solyc08g082760.2.1 & -0.85 & 0.55 \\
\hline solyc01g007540.2.1 & -0.85 & 0.56 \\
\hline solyc03g097360.2.1 & -0.84 & 0.56 \\
\hline solyc00g230080.1.1 & -0.84 & 0.56 \\
\hline solyc10g081530.1.1 & -0.84 & 0.56 \\
\hline solyc01g107660.2.1 & -0.84 & 0.56 \\
\hline solyc05g026550.2.1 & -0.83 & 0.56 \\
\hline solyc00g019740.1.1 & -0.83 & 0.56 \\
\hline solyc03g098590.2.1 & -0.83 & 0.56 \\
\hline solyc04g078380.1.1 & -0.82 & 0.57 \\
\hline solyc09g055800.1.1 & -0.82 & 0.57 \\
\hline solyc05g055760.2.1 & -0.81 & 0.57 \\
\hline solyc05g046390.2.1 & -0.81 & 0.57 \\
\hline solyc02g080540.1.1 & -0.81 & 0.57 \\
\hline solyc06g082980.2.1 & -0.81 & 0.57 \\
\hline solyc05g054960.2.1 & -0.80 & 0.57 \\
\hline solyc11g017200.1.1 & -0.80 & 0.57 \\
\hline solyc04g015370.2.1 & -0.79 & 0.58 \\
\hline solyc09g011580.2.1 & -0.79 & 0.58 \\
\hline solyc12g057120.1.1 & -0.79 & 0.58 \\
\hline solyc07g056420.2.1 & -0.78 & 0.58 \\
\hline solyc02g068450.2.1 & -0.78 & 0.58 \\
\hline solyc06g054510.2.1 & -0.77 & 0.59 \\
\hline solyc03g093180.1.1 & -0.76 & 0.59 \\
\hline solyc07g056540.2.1 & -0.76 & 0.59 \\
\hline solyc01g096480.2.1 & -0.76 & 0.59 \\
\hline solyc02g012020.1.1 & -0.76 & 0.59 \\
\hline solyc00g020940.1.1 & -0.76 & 0.59 \\
\hline solyc05g007600.1.1 & -0.76 & 0.59 \\
\hline
\end{tabular}




\begin{tabular}{|c|c|c|}
\hline solyc07g006490.2.1 & -0.75 & 0.59 \\
\hline solyc02g070770.2.1 & -0.75 & 0.60 \\
\hline solyc07g065820.2.1 & -0.75 & 0.60 \\
\hline solyc12g099240.1.1 & -0.74 & 0.60 \\
\hline solyc12g013900.1.1 & -0.74 & 0.60 \\
\hline solyc10g007670.2.1 & -0.74 & 0.60 \\
\hline solyc03g115030.2.1 & -0.74 & 0.60 \\
\hline solyc06g075810.2.1 & -0.74 & 0.60 \\
\hline solyc08g029160.1.1 & -0.73 & 0.60 \\
\hline solyc12g056250.1.1 & -0.72 & 0.61 \\
\hline solyc01g103750.2.1 & -0.71 & 0.61 \\
\hline solyc08g080630.2.1 & -0.71 & 0.61 \\
\hline solyc01g103710.2.1 & -0.71 & 0.61 \\
\hline solyc08g067020.2.1 & -0.71 & 0.61 \\
\hline solyc01g088040.2.1 & -0.71 & 0.61 \\
\hline solyc02g086460.2.1 & -0.71 & 0.61 \\
\hline solyc01g110390.2.1 & -0.70 & 0.61 \\
\hline solyc01g111650.2.1 & -0.70 & 0.61 \\
\hline solyc01g097350.2.1 & -0.70 & 0.62 \\
\hline solyc04g011900.2.1 & -0.70 & 0.62 \\
\hline solyc11g062130.1.1 & -0.69 & 0.62 \\
\hline solyc09g084470.2.1 & -0.69 & 0.62 \\
\hline solyc03g113240.2.1 & -0.69 & 0.62 \\
\hline solyc05g053310.2.1 & -0.69 & 0.62 \\
\hline solyc06g007540.2.1 & -0.69 & 0.62 \\
\hline solyc06g082680.2.1 & -0.69 & 0.62 \\
\hline solyc08g083010.2.1 & -0.68 & 0.62 \\
\hline solyc05g056290.2.1 & -0.68 & 0.62 \\
\hline solyc11g069410.1.1 & -0.68 & 0.62 \\
\hline solyc02g069820.2.1 & -0.68 & 0.62 \\
\hline solyc08g075750.2.1 & -0.68 & 0.62 \\
\hline solyc08g006930.2.1 & -0.68 & 0.62 \\
\hline solyc05g055810.2.1 & -0.68 & 0.63 \\
\hline solyc07g053830.2.1 & -0.68 & 0.63 \\
\hline solyc10g018590.1.1 & -0.67 & 0.63 \\
\hline solyc01g081190.2.1 & -0.67 & 0.63 \\
\hline solyc10g074540.1.1 & -0.67 & 0.63 \\
\hline solyc10g005100.2.1 & -0.67 & 0.63 \\
\hline solyc01g007490.2.1 & -0.67 & 0.63 \\
\hline solyc11g044530.1.1 & -0.67 & 0.63 \\
\hline solyc04g008710.2.1 & -0.66 & 0.63 \\
\hline solyc12g088050.1.1 & -0.66 & 0.63 \\
\hline solyc01g058220.1.1 & -0.66 & 0.63 \\
\hline solyc06g067980.2.1 & -0.65 & 0.64 \\
\hline solyc03g119700.2.1 & -0.65 & 0.64 \\
\hline
\end{tabular}




\begin{tabular}{|c|c|c|}
\hline solyc05g012110.2.1 & -0.65 & 0.64 \\
\hline solyc01g110540.2.1 & -0.65 & 0.64 \\
\hline solyc08g066030.2.1 & -0.64 & 0.64 \\
\hline solyc06g076450.2.1 & -0.64 & 0.64 \\
\hline solyc10g012410.2.1 & -0.64 & 0.64 \\
\hline solyc04g072230.2.1 & -0.64 & 0.64 \\
\hline solyc03g078000.2.1 & -0.64 & 0.64 \\
\hline solyc01g086640.2.1 & -0.64 & 0.64 \\
\hline solyc01g096240.2.1 & -0.64 & 0.64 \\
\hline solyc01g088610.2.1 & -0.63 & 0.65 \\
\hline solyc06g009630.1.1 & -0.63 & 0.65 \\
\hline solyc08g079620.2.1 & -0.63 & 0.65 \\
\hline solyc03g119460.2.1 & -0.63 & 0.65 \\
\hline solyc01g007290.1.1 & -0.63 & 0.65 \\
\hline solyc01g102960.2.1 & 0.63 & 1.55 \\
\hline solyc10g080770.1.1 & 0.63 & 1.55 \\
\hline solyc08g006430.2.1 & 0.63 & 1.55 \\
\hline solyc11g040050.1.1 & 0.63 & 1.55 \\
\hline solyc06g064460.2.1 & 0.63 & 1.55 \\
\hline solyc03g013110.1.1 & 0.64 & 1.56 \\
\hline solyc12g020050.1.1 & 0.64 & 1.56 \\
\hline solyc08g077030.2.1 & 0.65 & 1.57 \\
\hline solyc11g005690.1.1 & 0.65 & 1.57 \\
\hline solyc08g068870.2.1 & 0.65 & 1.57 \\
\hline solyc07g008350.2.1 & 0.66 & 1.58 \\
\hline solyc01g100450.1.1 & 0.66 & 1.58 \\
\hline solyc08g080610.1.1 & 0.66 & 1.58 \\
\hline solyc12g014490.1.1 & 0.66 & 1.58 \\
\hline solyc01g057700.1.1 & 0.67 & 1.59 \\
\hline solyc10g055200.1.1 & 0.67 & 1.59 \\
\hline solyc11g006250.1.1 & 0.67 & 1.59 \\
\hline solyc06g082560.1.1 & 0.67 & 1.60 \\
\hline solyc10g075150.1.1 & 0.67 & 1.60 \\
\hline solyc01g009810.2.1 & 0.68 & 1.60 \\
\hline solyc05g006320.2.1 & 0.68 & 1.60 \\
\hline solyc02g068420.2.1 & 0.68 & 1.60 \\
\hline solyc01g008620.2.1 & 0.68 & 1.60 \\
\hline solyc02g014310.2.1 & 0.68 & 1.60 \\
\hline solyc02g082920.2.1 & 0.68 & 1.61 \\
\hline solyc01g068050.2.1 & 0.69 & 1.61 \\
\hline solyc02g055360.1.1 & 0.69 & 1.61 \\
\hline solyc02g078350.2.1 & 0.69 & 1.61 \\
\hline solyc03g058950.2.1 & 0.69 & 1.61 \\
\hline solyc06g065540.2.1 & 0.69 & 1.61 \\
\hline
\end{tabular}




$\begin{array}{lll}\text { solyc08g080040.2.1 } & 0.69 & 1.61 \\ \text { solyc11g013450.1.1 } & 0.69 & 1.61 \\ \text { solyc04g078200.2.1 } & 0.69 & 1.61 \\ \text { solyc01g094540.2.1 } & 0.69 & 1.61 \\ \text { solyc07g061800.2.1 } & 0.69 & 1.62 \\ \text { solyc04g076190.1.1 } & 0.69 & 1.62 \\ \text { solyc12g098780.1.1 } & 0.70 & 1.62 \\ \text { solyc06g066060.2.1 } & 0.70 & 1.63 \\ \text { solyc02g083320.2.1 } & 0.70 & 1.63 \\ \text { solyc12g099650.1.1 } & 0.71 & 1.63 \\ \text { solyc02g069190.2.1 } & 0.71 & 1.64 \\ \text { solyc09g098620.1.1 } & 0.71 & 1.64 \\ \text { solyc10g006560.2.1 } & 0.71 & 1.64 \\ \text { solyc06g076570.1.1 } & 0.72 & 1.65 \\ \text { solyc01g097240.2.1 } & 0.72 & 1.65 \\ \text { solyc03g005580.2.1 } & 0.73 & 1.65 \\ \text { solyc01g068150.2.1 } & 0.73 & 1.65 \\ \text { solyc04g074040.2.1 } & 0.73 & 1.66 \\ \text { solyc05g052240.2.1 } & 0.73 & 1.66 \\ \text { solyc11g005170.1.1 } & 0.74 & 1.67 \\ \text { solyc08g079900.1.1 } & 0.74 & 1.67 \\ \text { solyc11g066840.1.1 } & 0.74 & 1.67 \\ \text { solyc10g083330.1.1 } & 0.74 & 1.68 \\ \text { solyc01g088140.2.1 } & 0.75 & 1.68 \\ \text { solyc09g015000.2.1 } & 0.75 & 1.68 \\ \text { solyc03g117510.2.1 } & 0.76 & 1.69 \\ \text { solyc01g108160.2.1 } & 0.77 & 1.70 \\ \text { solyc10g081100.1.1 } & 0.77 & 1.71 \\ \text { solyc09g015020.1.1 } & 0.77 & 1.71 \\ \text { solyc03g071560.2.1 } & 0.77 & 1.71 \\ \text { solyc09g083380.2.1 } & 0.78 & 1.71 \\ \text { solyc09g072560.2.1 } & 0.80 & 1.74 \\ \text { solyc09g018010.2.1 } & 0.80 & 1.74 \\ \text { solyc03g118810.1.1 } & 0.80 & 1.75 \\ \text { solyc10g075060.1.1 } & 0.81 & 1.75 \\ \text { solyc00g174340.1.1 } & 0.81 & 1.75 \\ \text { solyc07g008140.2.1 } & 0.82 & 1.77 \\ \text { solyc02g084340.1.1 } & 0.83 & 1.77 \\ \text { solyc01g005380.2.1 } & 0.84 & 1.79 \\ \text { solyc07g008940.2.1 } & 0.84 & 1.79 \\ \text { solyc08g007680.1.1 } & 0.84 & 1.79 \\ \text { solyc09g098600.2.1 } & 0.84 & \\ \text { solyc10g075110.1.1 } & 0.85 & \\ \text { solyc11g066130.1.1 } & 0.86 & 0.86 \\ \text { solyc06g062850.2.1 } & 0.89 & \\ & & 0.79 \\ & \end{array}$




\begin{tabular}{|c|c|c|}
\hline solyc08g079870.1.1 & 0.92 & 1.89 \\
\hline solyc03g046260.1.1 & 0.93 & 1.90 \\
\hline solyc11g005910.1.1 & 0.93 & 1.90 \\
\hline solyc08g079920.1.1 & 0.93 & 1.90 \\
\hline solyc06g071040.2.1 & 0.94 & 1.92 \\
\hline solyc03g007170.2.1 & 0.95 & 1.93 \\
\hline solyc09g082340.2.1 & 0.95 & 1.94 \\
\hline solyc02g093600.2.1 & 0.97 & 1.96 \\
\hline solyc04g074000.2.1 & 0.98 & 1.97 \\
\hline solyc01g097270.2.1 & 0.98 & 1.97 \\
\hline solyc05g049950.2.1 & 1.00 & 2.00 \\
\hline solyc10g075100.1.1 & 1.01 & 2.01 \\
\hline solyc08g080720.2.1 & 1.03 & 2.04 \\
\hline solyc08g023660.2.1 & 1.04 & 2.05 \\
\hline solyc02g082700.2.1 & 1.06 & 2.09 \\
\hline solyc03g032130.2.1 & 1.09 & 2.13 \\
\hline solyc11g020330.1.1 & 1.11 & 2.16 \\
\hline solyc09g025210.2.1 & 1.15 & 2.21 \\
\hline solyc03g020030.2.1 & 1.16 & 2.24 \\
\hline solyc11g020960.1.1 & 1.30 & 2.45 \\
\hline solyc05g009030.2.1 & 1.31 & 2.49 \\
\hline solyc03g098790.1.1 & 1.32 & 2.50 \\
\hline solyc07g041910.2.1 & 1.38 & 2.61 \\
\hline solyc07g041920.2.1 & 1.47 & 2.77 \\
\hline solyc00g145170.1.1 & 1.50 & 2.84 \\
\hline solyc03g098710.1.1 & 1.63 & 3.10 \\
\hline solyc03g082420.2.1 & 1.74 & 3.34 \\
\hline solyc12g088010.1.1 & 2.00 & 4.00 \\
\hline \multicolumn{3}{|l|}{ Embryo } \\
\hline solyc02g084240.2.1 & -1.66 & 0.32 \\
\hline solyc08g008260.2.1 & -1.57 & 0.34 \\
\hline solyc06g083230.2.1 & -1.26 & 0.42 \\
\hline solyc02g036460.2.1 & -1.21 & 0.43 \\
\hline solyc06g005280.1.1 & -1.11 & 0.46 \\
\hline solyc05g014160.2.1 & -1.05 & 0.48 \\
\hline solyc02g070010.1.1 & -0.94 & 0.52 \\
\hline solyc01g087170.2.1 & -0.90 & 0.53 \\
\hline solyc08g074940.2.1 & -0.82 & 0.57 \\
\hline solyc05g009240.2.1 & -0.66 & 0.63 \\
\hline solyc03g058330.2.1 & -0.66 & 0.63 \\
\hline solyc02g084840.2.1 & -0.64 & 0.64 \\
\hline solyc06g069260.1.1 & -0.64 & 0.64 \\
\hline solyc10g078770.1.1 & -0.63 & 0.65 \\
\hline
\end{tabular}




\begin{tabular}{|c|c|c|}
\hline solyc09g008980.1.1 & -0.61 & 0.66 \\
\hline solyc07g064770.1.1 & -0.59 & 0.66 \\
\hline solyc05g008510.2.1 & -0.57 & 0.68 \\
\hline solyc01g016970.1.1 & -0.56 & 0.68 \\
\hline solyc01g008950.2.1 & 0.55 & 1.46 \\
\hline solyc12g042650.1.1 & 0.56 & 1.48 \\
\hline solyc08g080570.2.1 & 0.56 & 1.48 \\
\hline solyc12g015880.1.1 & 0.58 & 1.49 \\
\hline solyc01g100390.2.1 & 0.59 & 1.51 \\
\hline solyc07g044760.2.1 & 0.59 & 1.51 \\
\hline solyc11g043200.1.1 & 0.61 & 1.53 \\
\hline solyc11g033280.1.1 & 0.61 & 1.53 \\
\hline solyc03g111140.2.1 & 0.61 & 1.53 \\
\hline solyc08g075160.2.1 & 0.62 & 1.53 \\
\hline solyc02g078100.2.1 & 0.63 & 1.55 \\
\hline solyc04g078920.2.1 & 0.63 & 1.55 \\
\hline solyc03g093160.2.1 & 0.63 & 1.55 \\
\hline solyc10g005670.1.1 & 0.64 & 1.56 \\
\hline solyc08g014000.2.1 & 0.64 & 1.56 \\
\hline solyc10g083720.1.1 & 0.67 & 1.59 \\
\hline solyc09g091000.2.1 & 0.68 & 1.60 \\
\hline solyc12g009020.1.1 & 0.68 & 1.60 \\
\hline solyc06g074980.2.1 & 0.71 & 1.63 \\
\hline solyc06g005360.2.1 & 0.71 & 1.64 \\
\hline solyc04g064770.1.1 & 0.76 & 1.70 \\
\hline solyc09g092380.2.1 & 0.77 & 1.71 \\
\hline solyc02g068130.2.1 & 0.77 & 1.71 \\
\hline solyc06g005160.2.1 & 0.81 & 1.75 \\
\hline solyc09g082990.2.1 & 0.83 & 1.78 \\
\hline solyc03g025720.2.1 & 0.87 & 1.82 \\
\hline solyc01g100760.2.1 & 0.87 & 1.83 \\
\hline solyc10g086150.1.1 & 0.87 & 1.83 \\
\hline solyc01g006580.2.1 & 0.89 & 1.85 \\
\hline solyc00g323130.2.1 & 0.96 & 1.95 \\
\hline solyc02g082760.2.1 & 0.98 & 1.97 \\
\hline solyc12g094620.1.1 & 1.00 & 2.00 \\
\hline solyc02g084850.2.1 & 1.06 & 2.08 \\
\hline solyc02g014310.2.1 & 1.08 & 2.11 \\
\hline solyc07g042550.2.1 & 1.13 & 2.19 \\
\hline solyc03g083440.2.1 & 1.15 & 2.22 \\
\hline solyc02g093040.2.1 & 1.23 & 2.35 \\
\hline \multicolumn{3}{|l|}{ Seed-coat } \\
\hline solyc06g009210.2.1 & -1.65 & 0.32 \\
\hline solyc09g066100.2.1 & -1.16 & 0.45 \\
\hline
\end{tabular}




\begin{tabular}{|c|c|c|}
\hline solyc04g078450.2.1 & -1.13 & 0.46 \\
\hline solyc04g071610.2.1 & -1.11 & 0.46 \\
\hline solyc12g055940.1.1 & -0.84 & 0.56 \\
\hline solyc06g084020.2.1 & -0.78 & 0.58 \\
\hline solyc02g071760.2.1 & -0.74 & 0.60 \\
\hline solyc09g083380.2.1 & -0.72 & 0.61 \\
\hline solyc08g016510.2.1 & -0.67 & 0.63 \\
\hline solyc04g051730.1.1 & -0.66 & 0.63 \\
\hline solyc07g056460.2.1 & -0.66 & 0.63 \\
\hline solyc02g085050.2.1 & -0.65 & 0.64 \\
\hline solyc06g007470.2.1 & -0.63 & 0.65 \\
\hline solyc04g007770.2.1 & -0.62 & 0.65 \\
\hline solyc10g084400.1.1 & -0.60 & 0.66 \\
\hline solyc02g085740.2.1 & -0.58 & 0.67 \\
\hline solyc03g005940.2.1 & -0.58 & 0.67 \\
\hline solyc07g049260.2.1 & -0.58 & 0.67 \\
\hline solyc07g062610.2.1 & -0.56 & 0.68 \\
\hline solyc10g084350.1.1 & -0.56 & 0.68 \\
\hline solyc01g080160.2.1 & -0.56 & 0.68 \\
\hline solyc03g025440.2.1 & -0.55 & 0.68 \\
\hline solyc07g062860.2.1 & -0.55 & 0.68 \\
\hline solyc10g055800.1.1 & 0.55 & 1.47 \\
\hline solyc01g107990.2.1 & 0.56 & 1.47 \\
\hline solyc08g080640.1.1 & 0.57 & 1.48 \\
\hline solyc07g048090.1.1 & 0.58 & 1.49 \\
\hline solyc03g118040.2.1 & 0.58 & 1.50 \\
\hline solyc01g098770.1.1 & 0.59 & 1.50 \\
\hline solyc06g083300.2.1 & 0.59 & 1.51 \\
\hline solyc02g085420.2.1 & 0.62 & 1.54 \\
\hline solyc08g081790.1.1 & 0.62 & 1.54 \\
\hline solyc07g055320.2.1 & 0.62 & 1.54 \\
\hline solyc10g047220.1.1 & 0.63 & 1.55 \\
\hline solyc11g042930.1.1 & 0.65 & 1.56 \\
\hline solyc09g084450.2.1 & 0.65 & 1.57 \\
\hline solyc01g096450.2.1 & 0.66 & 1.58 \\
\hline solyc01g088370.2.1 & 0.67 & 1.60 \\
\hline solyc08g068310.2.1 & 0.68 & 1.60 \\
\hline solyc06g071770.2.1 & 0.70 & 1.63 \\
\hline solyc09g007850.2.1 & 0.73 & 1.65 \\
\hline solyc12g015880.1.1 & 0.73 & 1.66 \\
\hline solyc02g087880.2.1 & 0.74 & 1.68 \\
\hline solyc05g018240.2.1 & 0.83 & 1.78 \\
\hline solyc11g022590.1.1 & 0.85 & 1.80 \\
\hline
\end{tabular}




$\begin{array}{lll}\text { solyc03g093160.2.1 } & 0.85 & 1.80 \\ \text { solyc06g007610.2.1 } & 0.88 & 1.85 \\ \text { solyc01g005820.2.1 } & 0.95 & 1.93 \\ \text { solyc05g053780.2.1 } & 1.02 & 2.03 \\ \text { solyc07g006560.2.1 } & 1.04 & 2.05 \\ \text { solyc04g072160.2.1 } & 1.73 & 3.31\end{array}$

${ }^{\mathrm{a}}$ Proteins that have passed $t$-test followed by FDR correction $(p<0.05)$ when comparing protein abundance levels between Al-treated and non-treated control groups. ${ }^{\mathrm{b}}$ Accession number in the International Tomato Annotation Group (ITAG) 2.4 protein database. ${ }^{c}$ Log $^{2}$ transformed ratio from Al-treated to control non-treated groups, these datasets were used for pathway analysis using Mapman. ${ }^{d}$ Ratio of protein abundance level between Al-treated $(T)$ to non-treated control (C) groups. 
Table S4. Functional pathways of leaf proteins annotated using Mapman ${ }^{\mathrm{a}}$

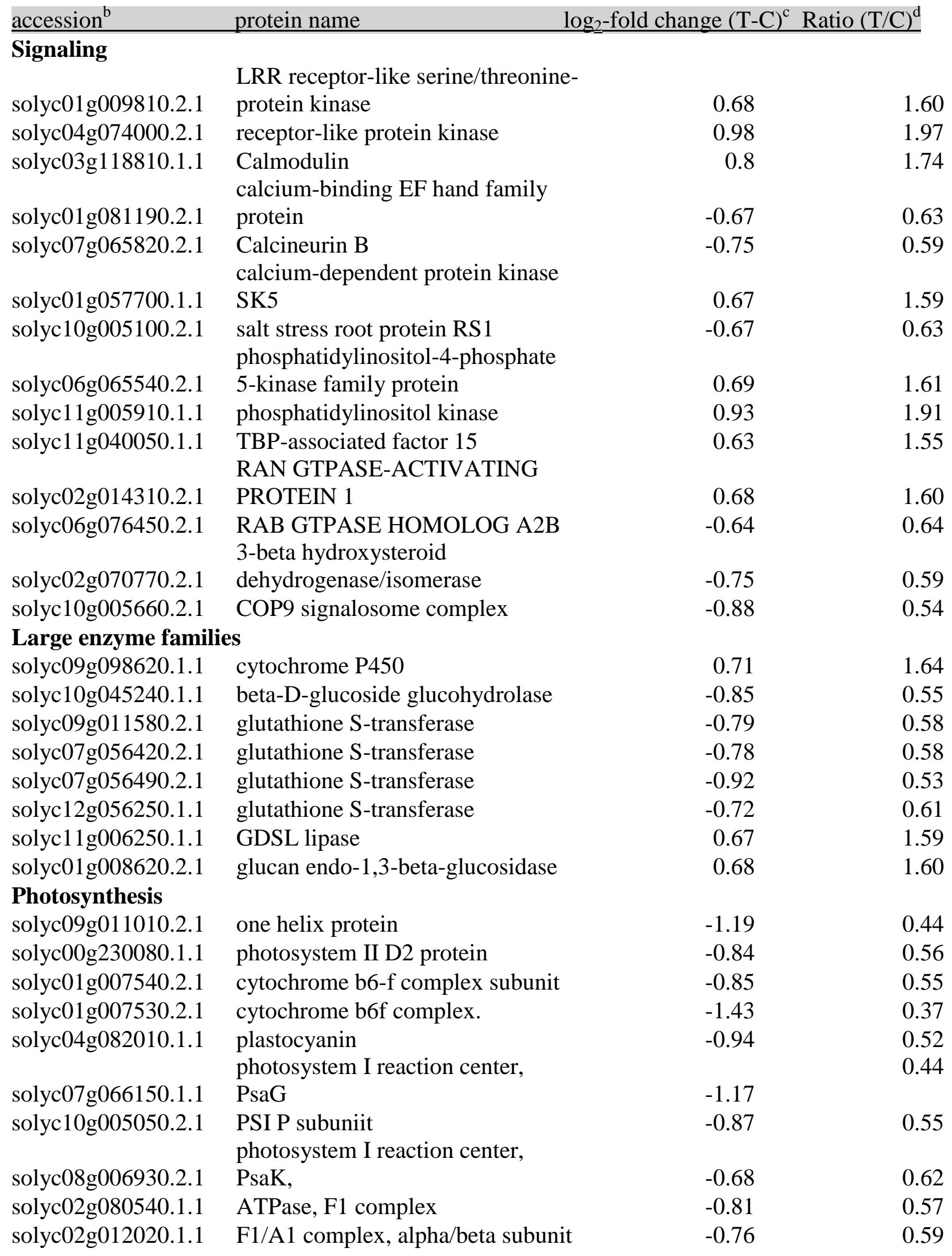




\begin{tabular}{|c|c|c|c|}
\hline \multicolumn{4}{|l|}{ Photostorespiration } \\
\hline solyc10g007600.2.1 & glycolate oxidase & -0.92 & 0.53 \\
\hline solyc07g056540.2.1 & glycolate oxidase & -0.76 & 0.59 \\
\hline solyc $08 \mathrm{~g} 048250.2 .1$ & glycolate oxidase & -1.26 & 0.42 \\
\hline solyc12g099930.1.1 & alanine-glyoxylate transaminase & -0.93 & 0.52 \\
\hline \multicolumn{4}{|c|}{ Mitochondrial activities } \\
\hline solyc07g053830.2.1 & ADP/ATP translocase & -0.68 & 0.62 \\
\hline solyc11g065830.1.1 & dicarboxylate transporter 1 & -1.33 & 0.40 \\
\hline solyc06g075810.2.1 & NADH-ubiquinone oxidoreductase & -0.74 & 0.60 \\
\hline solyc06g007540.2.1 & cytochrome b-c1 & -0.69 & 0.62 \\
\hline solyc06g082680.2.1 & $\begin{array}{l}\text { cytochrome b-c1 } \\
\text { ubiquinol-cytochrome c reductase }\end{array}$ & -0.69 & 0.62 \\
\hline solyc08g067020.2.1 & complex $14 \mathrm{kDa}$ protein & -0.71 & 0.61 \\
\hline solyc01g103220.2.1 & $\begin{array}{l}\text { cytochrome } \mathrm{c} \text {, class IA/ IB } \\
\text { subunit VIb of cytochrome c }\end{array}$ & -0.91 & 0.53 \\
\hline solyc12g057120.1.1 & $\begin{array}{l}\text { oxidase } \\
\text { cytochrome c oxidase polypeptide }\end{array}$ & -0.79 & 0.58 \\
\hline solyc01g079420.2.1 & Vc-2 & -0.93 & \\
\hline solyc03g095190.2.1 & $\begin{array}{l}\text { ATPase, F1 complex, delta/epsilon } \\
\text { subunit }\end{array}$ & -1.19 & 0.44 \\
\hline solyc00g019740.1.1 & ATPase, F0 complex, subunit 8 & -0.83 & 0.56 \\
\hline solyc $05 \mathrm{~g} 052150.2 .1$ & ATP synthase subunit delta\&apos & -1.23 & 0.43 \\
\hline solyc05g052140.2.1 & ATP synthase delta chain & -1.08 & 0.47 \\
\hline \multicolumn{4}{|l|}{ Transcription } \\
\hline solyc03g097360.2.1 & BolA-like protein & -0.84 & \\
\hline solyc06g062850.2.1 & zinc finger, PHD-finger & 0.89 & 1.85 \\
\hline solyc07g054960.1.1 & MYB63 & -0.88 & 0.54 \\
\hline solyc10g080770.1.1 & bZIP transcription factor & 0.63 & 1.55 \\
\hline solyc11g066840.1.1 & histone deacetylase-like protei & 0.74 & 1.67 \\
\hline solyc02g082700.2.1 & high mobility group protein & 1.06 & 2.08 \\
\hline solyc02g078350.2.1 & $\begin{array}{l}\text { pentatricopeptide repeat } \\
\text { AT-hook motif nuclear localized }\end{array}$ & 0.69 & 1.61 \\
\hline solyc08g077030.2.1 & protein 13 & 0.65 & 1.57 \\
\hline solyc12g020050.1.1 & pentatricopeptide repeat & 0.64 & 1.56 \\
\hline solyc01g005380.2.1 & $\begin{array}{l}\text { SET domain containing protein } \\
\text { histone-lysine N-methyltransferase, }\end{array}$ & 0.84 & 1.79 \\
\hline solyc03g093700.1.1 & H3 lysine- 9 specific 5 & -1.16 & 0.45 \\
\hline solyc01g008270.2.1 & prefoldin alpha subunit & -1.13 & 0.46 \\
\hline solyc08g068870.2.1 & peptidase A1 & 0.65 & 1.57 \\
\hline solyc04g076190.1.1 & peptidase A1 & 0.69 & \\
\hline \multicolumn{4}{|l|}{ Stress } \\
\hline solyc01g086640.2.1 & $\begin{array}{l}\text { auxin-independent growth } \\
\text { promoter, } \\
\text { 3-beta-hydroxysteroid-Delta8 }\end{array}$ & -0.64 & 0.64 \\
\hline solyc06g082980.2.1 & delta7-isomerase & -0.81 & 0.57 \\
\hline
\end{tabular}


solyc08g080040.2.1 solyc12g088050.1.1 solyc12g088050.1.1 solyc01g007490.2.1 solyc08g079620.2.1 solyc08g007680.1.1 solyc08g079920.1.1 solyc08g079900.1.1 solyc08g079870.1.1 solyc07g041910.2.1 solyc07g041920.2.1 solyc08g075750.2.1 solyc03g098590.2.1

solyc01g111650.2.1 solyc01g096480.2.1 solyc04g078910.2.1 solyc $10 \mathrm{~g} 078920.1 .1$ solyc08g029160.1.1 solyc03g025840.2.1 solyc09g011580.2.1 solyc07g056420.2.1 solyc07g056490.2.1 solyc12g056250.1.1 solyc10g074540.1.1

solyc01g009810.2.1 solyc04g074000.2.1 solyc03g118810.1.1 solyc01g081190.2.1 solyc01g097350.2.1 solyc07g065820.2.1 solyc01g057700.1.1

solyc10g005100.2.1

solyc06g065540.2.1 solyc11g005910.1.1 solyc11g040050.1.1 solyc02g014310.2.1 solyc06g076450.2.1 solyc02g070770.2.1 solyc $10 \mathrm{~g} 005660.2 .1$ solyc10g080770.1.1 leucocyanidin oxygenase

rhamnogalacturonate lyase

rhamnogalacturonate lyase

peptidase S14

peptidase S14

peptidase $\mathrm{S} 8$

peptidase S8

peptidase S8

peptidase $\mathrm{S} 8$

peptidase C1A

peptidase $\mathrm{C} 1 \mathrm{~A}$

peptidase $\mathrm{S} 14$

zinc finger

ubiquitin ligase, SCF complex, Skp

subunit

thioredoxin

thioredoxin

thioredoxin

cytochrome b5

cytochrome b561

gutathione S-transferase

glutathione S-transferase

glutathione S-transferase

glutathione S-transferase

phosphate-induced protein 1

BRASSINOSTEROID

INSENSITIVE 1-associated

receptor kinase 1

receptor like kinase, RLK

calcium-binding protein

calcium-binding protein

calcium-binding protein

Calcineurin B protein

calcium-dependent protein kinase

DREPP plasma membrane

polypeptide family protein

phosphatidylinositol-4-phosphate

5-kinase

PI3-kinase

zinc finger protein 265 ,

Ran GTPase

Ras-related protein Rab2BV

Flavin reductase

COP9 signalosome subunit 6

Myb-related protein Zm1
0.69

$-0.66$

$-0.66$

$-0.67$

$-0.63$

0.84

0.93

0.74

0.92

1.38

1.47

$-0.68$

$-0.83$

$-0.7$

$-0.76$

$-0.93$

$-0.99$

$-0.73$

$-1.15$

$-0.79$

$-0.78$

$-0.92$

$-0.72$

$-0.67$

0.68

0.98

0.8

$-0.67$

$-0.7$

$-0.75$

0.67

$-0.67$

0.69

0.93

0.63

0.68

$-0.64$

$-0.75$

$-0.88$

0.63
0.63

0.63

0.63

0.65

1.79

1.91

1.67

1.89

2.60

2.77

0.62

0.56

0.62

0.59

0.52

0.50

0.60

0.45

0.58

0.58

0.53

0.61

0.63

1.60

1.97

1.74

0.63

0.62

0.59

1.59

0.63

1.61

1.91

1.55

1.60

0.64

0.59

0.54

1.55 
solyc07g054960.1.1 Myb-related protein Zm1 $\quad-0.88$ isopentenyl-diphosphate delta-

solyc05g052240.2.1 chalcone-flavanone isomerase

${ }^{\mathrm{a}}$ Proteins that have passed $t$-test followed by FDR correction $(p<0.05)$ when comparing protein abundance levels between Al-treated and non-treated control groups. ${ }^{\mathrm{b}}$ Accession number in the International Tomato Annotation Group (ITAG) 2.4 protein database. ${ }^{c} \log _{2}$ transformed ratio from Al-treated to control non-treated group, these datasets were used for pathway analysis using Mapman. ${ }^{\mathrm{d}}$ Ratio of protein abundance level from Al treated $(\mathrm{T})$ to control $(\mathrm{C})$ non-treated groups. 